\title{
Acerca de la ocupación Inca del valle de Mala (Cañete, Lima)
}

\author{
Henry Tantaleán* \\ Omar Pinedo**
}

Resumen Se discuten nuestros planteamientos acerca de los últimas ocupaciones prehispánicas en el valle bajo de Mala producto de los trabajos arqueológicos realizados hasta la actualidad. En concreto, se discute la ocupación Inca del valle bajo de Mala como un proceso dialéctico que supuso el enfrentamiento de dos sociedades: la local y la invasora, en un área que hasta el momento se había asumido como de "vacío social" en la costa central.

Palabras clave Dialéctica, control, invasión, explotación, ideología.
Abstract
We disscuse the two last prehispanic ocuppations in the lower Mala valley as a con- sequence our archaeological research developemented to the present. Specifically, we discusse the Inca Occupation as a dialectical process that supossed the confron- tation of two societies: the local and the invaders in an area previously assumed as a "social vacuum" in the prehispanic central coast.

Keywords Dialectics, control, invasion, explotation, ideology.

* Departamento de Prehistoria. Universidad Autónoma de Barcelona, España. Correo electrónico: henrytantalean@yahoo.es

** Arqueólogo de la Universidad Nacional Mayor de San Marcos, Lima-Perú e investigador asociado al Instituto Cultural Rvna. Correo electrónico: avqi@yahoo.es 


\section{Introducción}

Desde el año 1996, los autores de este artículo desarrollamos investigaciones arqueológicas en el valle formado por las aguas del río Mala, ubicado al sur del departamento de Lima en la costa central del Perú (figura 1). Dichas investigaciones incluyeron la prospección arqueológica de la sección baja del valle, que comprende el tramo localizado entre la localidad de La Capilla (a unos $468 \mathrm{msnm}$ ) y la desembocadura del río Mala en el Océano Pacífico (alrededor de $32 \mathrm{~km}$ del recorridodel río) (figura 2).
Mediante estas investigaciones pudimos aproximarnos a los desarrollos sociales, económicos y políticos de esta zona. En primer lugar, reconocimos que para el denominado Periodo Intermedio Tardío o época de Desarrollos Regionales Tardíos (1100-1470 años de nuestra era) existió una sociedad que utilizó un estilo cerámico conocido en la literatura arqueológica andina como Puerto Viejo ${ }^{1}$ (Bonavía 1959) (figura3). En ese momento de nuestra formación académica la "asociación directa" entre asentamientos y estilo cerámico revelaría qué asentamientos

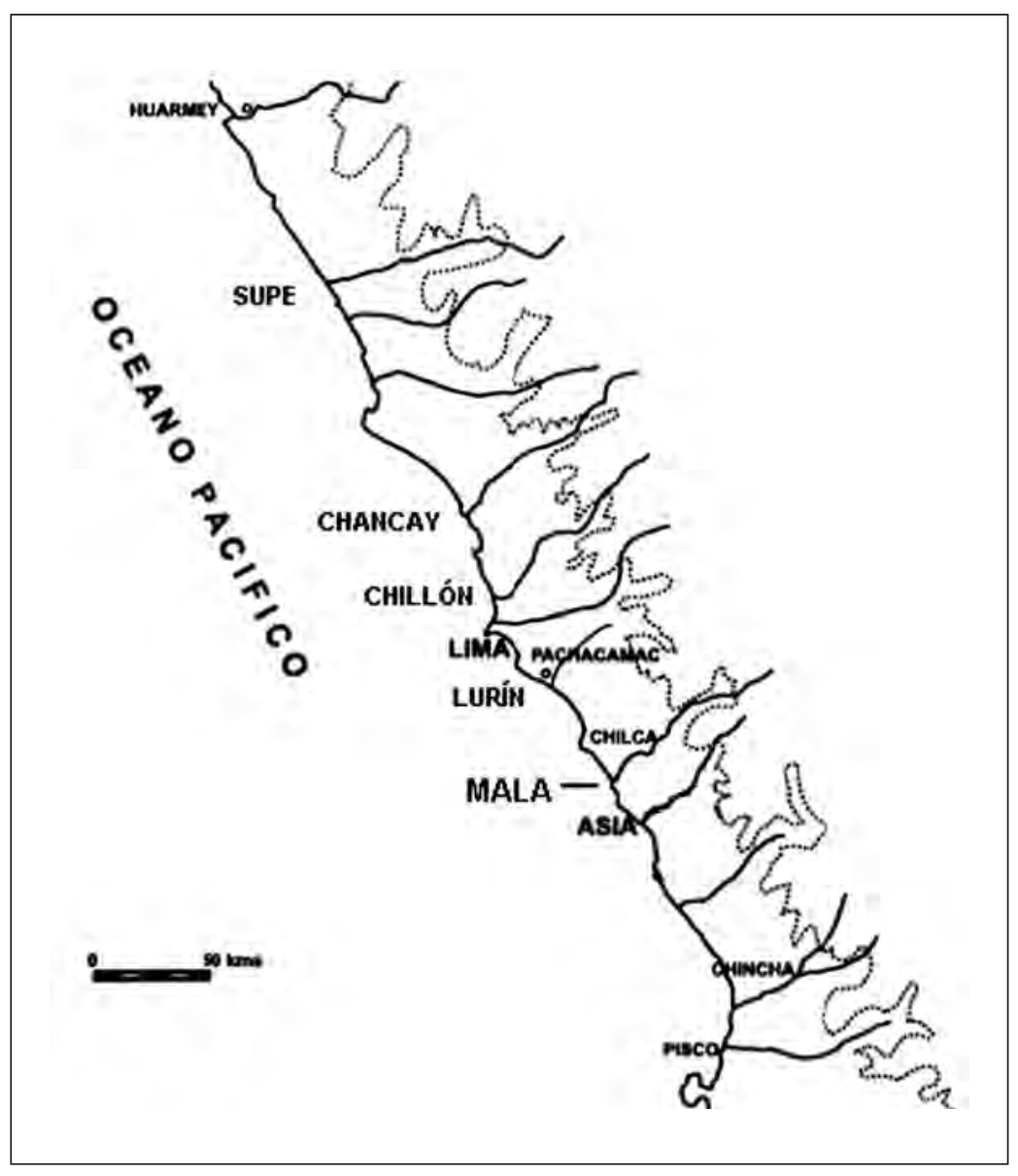

Figura 1. Mapa de la costa central. Valles vecinos al valle de Mala.

${ }^{1}$ Puerto Viejo es un sitio que se halla ubicado cerca al litoral, al norte de la desembocadura del río Mala. Fue allí donde Tabio hizo una recolección de 645 fragmentos de cerámica de superficie. El análisis de éstos, realizado por Bonavía, concluyó en la definición de un estilo cerámico. Por otra parte Engel (1982) que también encuentra este estilo en la Quebrada de Chilca nos ofrece un fechado absoluto para ella alrededor de los 1400 años d.n.e. 


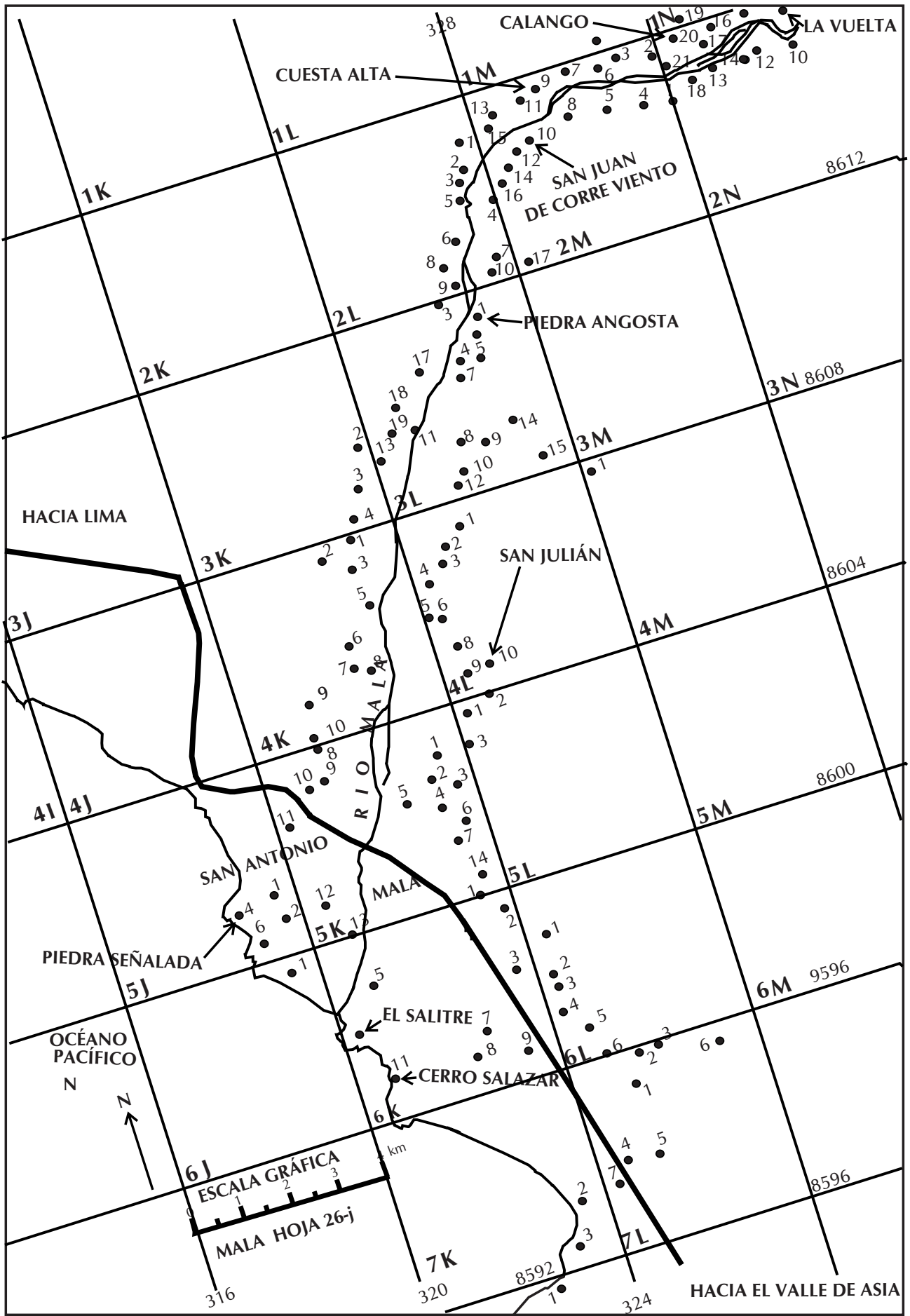

Figura 2. Plano de ubicación de los sitios arqueológicos en el valle de Mala, basado en Williams y Merino 1976. Resaltados los sitios señalados en el texto. 


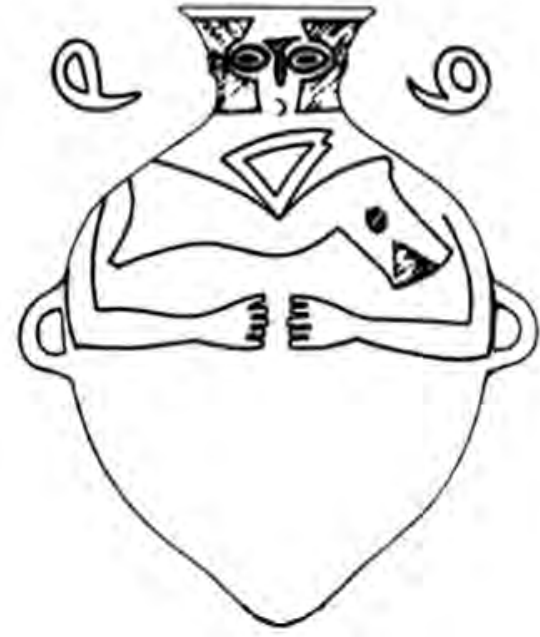

Figura 3. Cántaro "cara-gollete" típico del estilo cerámico Puerto Viejo. Tomado de Engel (1966).

pertenecerían a dicha sociedad, es decir, íbamos en busca de la "Cultura Puerto Viejo".

En segundo lugar, también teníamos como objetivo entender el impacto Inca en las sociedades locales y cómo se produjeron cambios sociales, económicos y políticos materializados en un nuevo patrón de asentamiento y la consecuente inclusión de elementos arquitectónicos extraños al valle hasta la llegada de los colonizadores castellanos en 1532.

Asimismo, nuestra investigación también esperaba comprender ciertos mecanismos de "integración religiosa” de la Costa Central prehispánica, en concreto el de la hegemonía religiosa del sitio de Pachacamac y su relación con los valles vecinos como el de Mala. El análisis de dichos mecanismos de integración político-religiosa siempre se habían abordado desde la etnohistoria y se basaba en relatos como el de los "hijos de Pachacamac", discurso que encubriría una estrategia de coerción ideológica iniciada en época pre-inca y luego consolidada para su beneficio por la clase dominante Inca. Por ello, esto será incluido aquí de manera que nos acerque a las estrategias de dominación Inca utilizadas en el valle de Mala.

\section{Características generales delárea de estudio}

Elvalle de Mala se encuentra al sur de Lima (a unos $84 \mathrm{~km}$ de la capital del Perú), en la provincia de Cañete. En la actualidad, nuestra área de estudio comprende los distritos de Santa Cruz de Flores, San Antonio, San Pedro de Mala y Calango.

El río Mala se origina en el flanco occidental de los Andes por la unión de los ríos Quinches y San Lorenzo y recorre $120 \mathrm{~km}$. En su recorrido el río atraviesa diversas formaciones ecológicas desde el desierto subtropical (próxima al litoral) hasta la estepa espinosa Montano Bajo y estepa Montano, todas ellas potenciales para la agricultura. A grandes rasgos, la parte del Mala que estudiamos está conformada por llanuras y colinas de relieve ondulado cerca al litoral (figura 4)y otra fuertemente accidentada ubicadas en los flancos de la cordillera occidental de los Andes.

El valle de Mala tiene en la actualidad una temperatura media de $18 \ddot{\mathrm{Y}}=$, la temperatura mínima extrema es de 10 ŸC y la máxima de 30 ŸC. La humedad relativa mínima es de 77 por ciento, la máxima, de 85 por ciento. Casi no hay precipitaciones. Tiene un clima semicálido y algunas zonas se caracterizan por el alto porcentaje de horas de sol como en la zona de Calango (entre 200 y 500 msnm). Cuando se produce el fenómeno de $\mathrm{El}$ Niñolas variaciones de la humedad son extremas, y tienen efectos sobre la producción agrícola. Un rasgo hidrológico que el río Mala comparte con los ríos de la costa peruana es su comportamiento estacional. Así, se registran momentos de gran descarga entre los meses de enero y marzo (cerca de 70 por ciento de la descarga anual), y otros de sensible escasez entre los meses de julio y octubre (cerca de 6 por ciento de ella), con períodos intermedios entre los meses de abril-junio y noviembre-diciembre. Pero a diferencia de lo que ocurre con muchos ríos de los diversos valles de la costa, el de Mala disminuye el caudal durante el año, peronunca se seca (Chávez 2002).

El área de nuestro estudio es mostrada en la figura 2 y, a grandes rasgos, comprende las áreas adyacentes al río. Una cuestión que condicionó el 


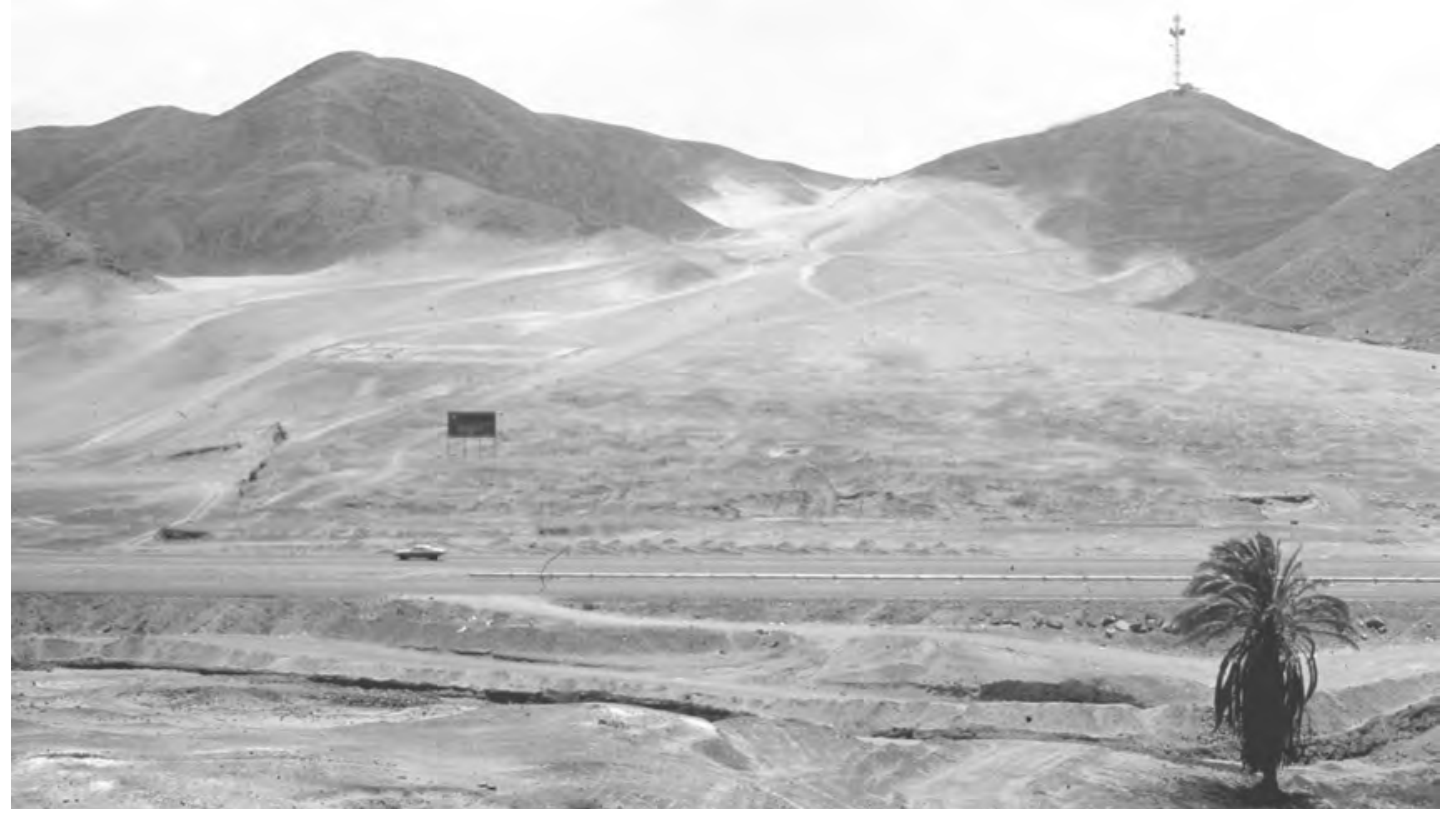

Figura 4. Paisaje del litoral en Mala. Aquí se encuentra el sitio prehispánico de Piedra Señalada (San Antonio), típico del Período Intermedio Tardio.

reconocimiento de sitios es que el valle ha estado expuesto a profundas transformaciones, producto de la intensa actividad agrícola, siendo en la actualidad difícil, por no decir imposible, ubicar asentamientos en la zona llana del fondo del valle en la que se encuentran los campos de cultivo. De manera que en la actualidad, la mayoría de sitios arqueológicos conocidos se encuentran en zonas denominadas "eriazas", casi siempre vecinas a las pendientes de los cerros o quebradas que no están sometidas a riego.

\section{Las investigaciones arqueológicas en el valle de Mala}

Las primeras investigaciones en este valle se dieron el siglo pasado, cuando el sacerdote Pedro Villar Córdova realizó diferentes visitas a las zonas arqueológicas el departamento de Lima y ayudado por los datos etnohistóricos iba describiendo y relacionando étnicamente a dichas áreas arqueológicas. En los datos recogidos en dichos recorridos, hace mención de numerosos sitios en el valle Mala y reconoce su gran riqueza arqueológica (VillarCórdova 1931:276-278).
Otras escuetas referencias arqueológicas del Valle de Mala provienen del "padre de la arqueología peruana” Julio C. Tello (1959), quien también menciona al sitio de El Salitre. Para Tello, las construcciones pertenecerían al Horizonte Medio (600-1000 d.n.e). Asimismo, los antropólogos norteamericanos Strong y Willey (1943) durante sus prospecciones en la costa sur reconocen varios sitios cercanos a la desembocadura del Mala entre los que mencionan a Ollería y Totoritas (ELSalitre), etc. Goldfried (1969) también se refiere a El Salitre en un artículo monográfico.

Frederick Engel, investigador que realizó extensas prospecciones en los valles de la costa peruana, también reconoció unos cuantos sitios arqueológicos en la parte baja del valle. Aunque las referencias de estos sitios son bastante sintéticas (Engel 1982), muchas descripciones inéditas producidas durante dichos reconocimientos y depositadas en los archivos del antiguo Centro de Investigaciones de Zonas Áridas son las más importantes de los sitios arqueológicos de la desembocadura del río Mala, algunos de ellos 
arrasados por el actual proceso de urbanización de dichas zonas (Tantaleán 1995).

A su vez el arquitecto Carlos Williams (1980) dentro de su planteamiento de la tradición arquitectónica de los "templos en U" de la costa central, señalaría al sitio de El Salitre "donde se encuentra un edificio con pozo ceremonial incorporado entre los dos brazos de una pirámide" (Williams 1980: 107). Sin embargo, dicha cuestión ya fue criticada por nosotros en su momento, descartando dicha datación relativa (Tantaléan y Pinedo s/f).

Para finalizar con los trabajos realizados en el valle bajo de Mala, agregaremos el texto presentado por Carmen Gabe (Gabe 2000) acerca de sus excavaciones en el sitio arqueológico denominado Cerro Salazar, sitio que ya describíamos en un primer acercamiento al área de estudio (Tantaleán 1995). Hay que destacar que el sitio en ese momento ya se hallaba bastante destruido, y prácticamente con los trabajos de Gabe se revelaba lo que ya se había denunciado en su momento: la destrucción sistemática del sitio Cerro Salazar. De todas formas, es necesario señalar que a la actualidad dicha información es la única de esta parte del valle, que ha sido publicada y en la que se ofrece información relevante para el área en época prehispánica.

Apesar de la escasa información arqueológica de la zona, nos propusimos trabajar en ella, ya que producto de estas circunstancias se percibía un aparente "vacío social" en la costa central prehispánica anterior a la llegada de los Incas (Eeckhout 1999: 463), el cual mayormente era cubierto asociando el valle de Mala con grupos sociales cercanos como el Ychma (v.gr. Bueno 1982: 14 y 25, Bazán del Campo 1992; citado en Morales: 1993: 542) que ocupaba principalmente los valles de Luríny Rimac.

\section{Metodología de la investigación}

Nuestro trabajo tuvo como punto de partida el inventario, catastroy delimitación del patrimonio arqueológico del valle de Mala realizado por Williams y Merino a petición del Instituto
Nacional de Cultura en el año 1976. Gracias a éste, pudimos realizar la prospección y reevaluación de todos los sitios arqueológicos de la zona baja, de una manera más fácil, y supuso dirigirnos al campo contando con una hipótesis a priori que planteaba que: "los asentamientos del Intermedio Tardio (1100-1470 d.n.e.) deberían estar asociados a un patrón arquitectónico reconocido en la zona de litoral y adicionalmente con cerámica Puerto Viejo" (Tantaleán 1996).

Por cuestiones de comodidad, nuestro recorrido se inició en la misma zona que lo hicieron Williams y Merino, vale decir en la localidad de La Capilla (a unos $468 \mathrm{msnm}$ ). En nuestra prospección, además del registro gráfico (croquis y fotografías), se tomaron notas de descripción de cada sitio, verificando la existencia de ocupaciones del Intermedio Tardío o Inca. A pesar de que abrigábamos la esperanza de localizar asentamientos más tempranos, durante nuestro recorrido, estos nofueron localizados.

Al iniciar nuestra prospección pensábamos que desde el sector de La Capilla encontraríamos asentamientos con características que habíamos reconocido en el litoral cercano a la desembocadura del río Mala en una prospección preliminar (Tantaleán 1995). Por el contrario, encontramos nuevos elementos arquitectónicos de construcción que nos sirvieron para definir un posible segundo grupo social, en la parte alta de nuestra prospección. Adicionalmente, encontramos muchos problemas para nuestro fechado relativo (mediante la cerámica asociada a la arquitectura) ya que algunos sitios de la zona alta, contenían poca cantidad de ésta. Finalmente, "bajando" por el valle encontramos los asentamientos que nos parecían conformar un mismo grupo con los de la zona del litoral. Éstos, además, estaban asociados agran cantidad de cerámica Puerto Viejo.

\section{Las sociedades locales del intermedio tardío del valle de Mala}

En un primer acercamiento a esta cuestión (ídem 1996) planteamos la presencia de dos sociedades para la parte que nos ocupa del valle de 
Mala. Una de ellas estaría asociada a grupos serranos y la otra asociada a las del litoral. Obviamente, esta división también obedecería a cuestiones topográficas o de explotación de recursos naturales concretos. Asimismo, planteábamos una relación económica entre ellas dentrode una red de intercambio de productos.

Aunque por el momento no lo tenemos bien definido, queremos adelantar algunas características de este supuesto grupo social de filiación serrana. Éste se caracterizaría por asentamientos pequeños (entre 1 y 3 hectáreas) con recintos rectangulares que se encuentran ubicados en pendientes de cerros (gracias a la construcción de terrazas) y/o cercanos a su base (aunque esto estaría justificado por la poca disponibilidad de tierras para habitación de esta parte donde el valle se estrecha). El material de construcción empleado es la piedra de cerro unida con argamasa de barroy revestida con barro. La cantidad de cerámica aquí hallada es poca con relación a los sitios asociados a cerámica Puerto Viejo. La misma es tosca en apariencia y sin decoración pintada (salvo algunas con impresiones circulares), todas pertenecientes a formas domésticas como ollas o cántaros. El color predominante es marrón y negro, por ser principalmente vasijas realizadas en hornos reductores. El patrón funerario constituiría un nuevo elemento diagnóstico para estos asentamientos ya que incluyen tumbas rectangulares dentro de las habitaciones a manera de mausoleos o "cajas funerarias" construidas sobre el nivel del piso. Algunos asentamientos de este grupo social son los de Pasaca, Gramadal o Cerro Colorado.

El límite territorial entre este grupo y el siguiente que describiremos se hallaría valle arriba de la localidad de Aspitias para la margen norte y cercano a la antigua Hacienda Tutumo para la margen sur (a la altura del cuadro 3L de la figura 3), justo cuando el valle comienza a ser más ancho dada la cercanía a la desembocadura del río Mala.

El segundo grupo y al cual nuestro trabajo estaba orientado a definir, poseía los elementos característicos y diagnósticos ya observados por nosotros en el litoral, como por ejemplo en el sitio de Piedra Señalada (figura 5), en la localidad de San Antonio (Tantaleán 1995). Es decir, se trataban de asentamientos nucleados que crecieron desordenadamente de acuerdo a las necesidades de su tiempo aún cuando contaban con espacio más amplios para la construcción de sus asentamientos, como las zonas llanas de la desembocadura del río y el litoral. En ninguno de los casos observados en el valle, dichos asentamientos humanos superaban las 50 unidades domésticas. Las mismas están caracterizadas por ser semisubterráneas y tener silos o depósitos cuadrangulares anexos a las construcciones. La técnica de construcción estaba constituida por paredes compuestas por piedras de campo semi-canteadas unidas con argamasa de barro. Los recintos poseían esquinas curvas, una característica significativa en dicho tipo de arquitectura. La gran cantidad de cerámica hallada en estos asentamientos nuevamente revelaba la gran producción de ésta y que se realizaría en la mayoría de los asentamientos (muchas veces se hallaba cerámica deformada o rota por su control deficiente en los hornos) (figura 5). Por el material de superficie

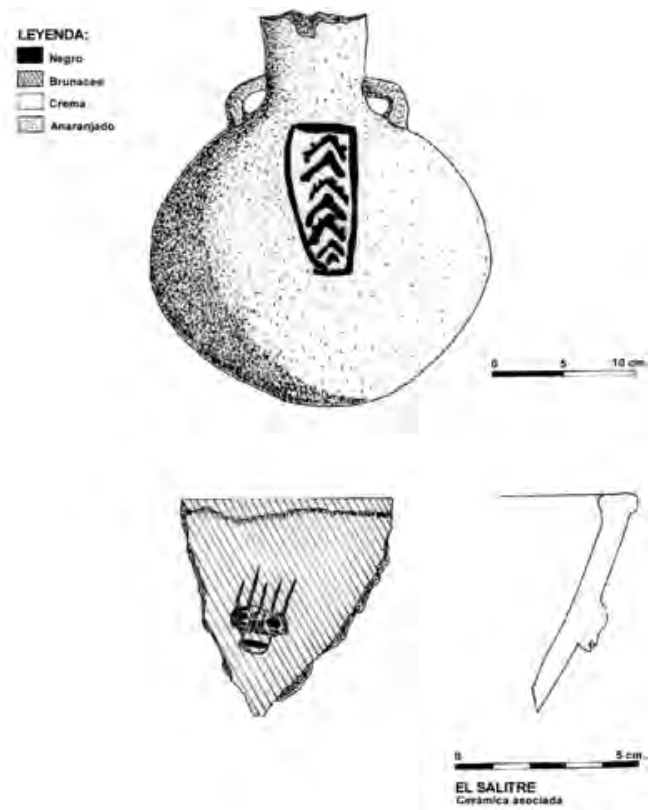

Figura 5. Cerámica Puerto Viejo recuperada en El Salitre. 
hallado en estos asentamientos se puede afirmar que la alimentación básica se realizaba aprovechandolos recursos marinos, aunque la dieta también incluiría vegetales como, por ejemplo, la calabaza. Asimismo, sectores casi siempre alejados del núcleo doméstico, conformados por espacios superficialmente limpios de plantas rectangulares delimitados por piedras, servirían para el secado de pescado u otros productos marinos. Asentamientos típicos de este grupo social serían los de San Julián, Las Flores, o Aspitias.

\section{La ocupación Inca del valle bajo de Mala}

La ocupación Inca de este valle, según datos etnohistóricos, se daría aproximadamente en 1476 durante la expansión del Imperio realizada por Túpac Inca Yupanqui (Bonavía 1991: 516). Dicha ocupación es más fácilmente reconocible en los asentamientos mayores Inca que en los asentamientos autóctonos, pues los últimos siguieron siendo utilizados sin mayores cambios durante esa época. Los principales sitios plenamente Inca, comenzando desde la parte superior de nuestra prospección, serían los de La Vuelta, Yuncaviri, Cuesta Alta, Corral Quemado, Piedra Angosta, Ollería, y ElSalitre, los mismos que estaban unidos por un camino Inca que corría paralelo al río. Dicho camino se encuentra bien conservado en el tramo entre la localidad de La Capilla y San Juan de Correviento, donde existió un gran asentamiento autóctono con posterior ocupación Inca. Asimismo, otro camino conectaría el valle de Mala con el de Chilca a través de una quebrada transversal que se inicia en Mala en la quebrada conocida como Cuesta Alta, donde además existió un sitio Inca de control. Una ruta similar uniría el valle de Mala con el de Asia a través de la Quebrada Millay(Coello 1993).

Asimismo, cabe señalar que la mayoría de los asentamientos con arquitectura Inca típica en este valle, se hallan emplazados en las quebradas que descienden hacia el río Mala. Si bien, estos lugares no parecen ser idóneos para la construcción de arquitectura administrativa por la probable descarga de agua y barro por estas quebradas en épocas lluviosas o por la poca defendibilidad que poseen, ${ }^{2}$ estos cumplirían una función más importante dentro de la región y que no sería otra que la del control del tránsito intervalles, en concreto el acceso a los valles de Chilca y Asia, zonas densamente pobladas antes y durante la presencia Inca (Engel 1982; Coello 1993).

Hay que remarcar que los asentamientos Inca del valle de Mala no concentrarían población civil, sino que más bien, se ofrecerían como espacios arquitectónicos para la residencia de los administradores de la política y religión Inca, actividades de gestión de los recursos locales (depósitos de alimentos, corrales), espacios para la producción controlada de bienes (cerámica, textiles, etc.) e inclusive sectores de personal controlado por el imperio (artesanos, soldados, mitimaes, etc.) tanto nativos comode otras regiones.

En el caso de Mala, al parecer, no se realizaron traslados de poblaciones ni concentración de las mismas alrededor de los nuevos asentamientos Inca como en otras áreas del Imperio Inca por lo que la mayoría de la arquitectura en los centros administrativos estaría relacionada con la gestión económica, política y religiosa del valle.

En este artículo, solamente nos ocuparemos de los sitios de La Vuelta y Piedra Angosta (y tangencialmente de El Salitre), los que gracias a los elementos imperiales Inca que incluyen, hemos reconocido como centros administrativos, según las características señaladas por Hyslop (1990). Ambos sitios son analizados aquí, pues representan ejemplos de dos tipos de asentamientos Inca en este valle y poseen en la actualidad un grado de conservación que permite observar la mayoría de sus componentes y planificación urbana originales.

\footnotetext{
${ }^{2}$ Ya que casi siempre se ubican en la parte más baja y adyacente al río, lo que supone un mínimo o inexistente control visual del paisaje circundante.
} 


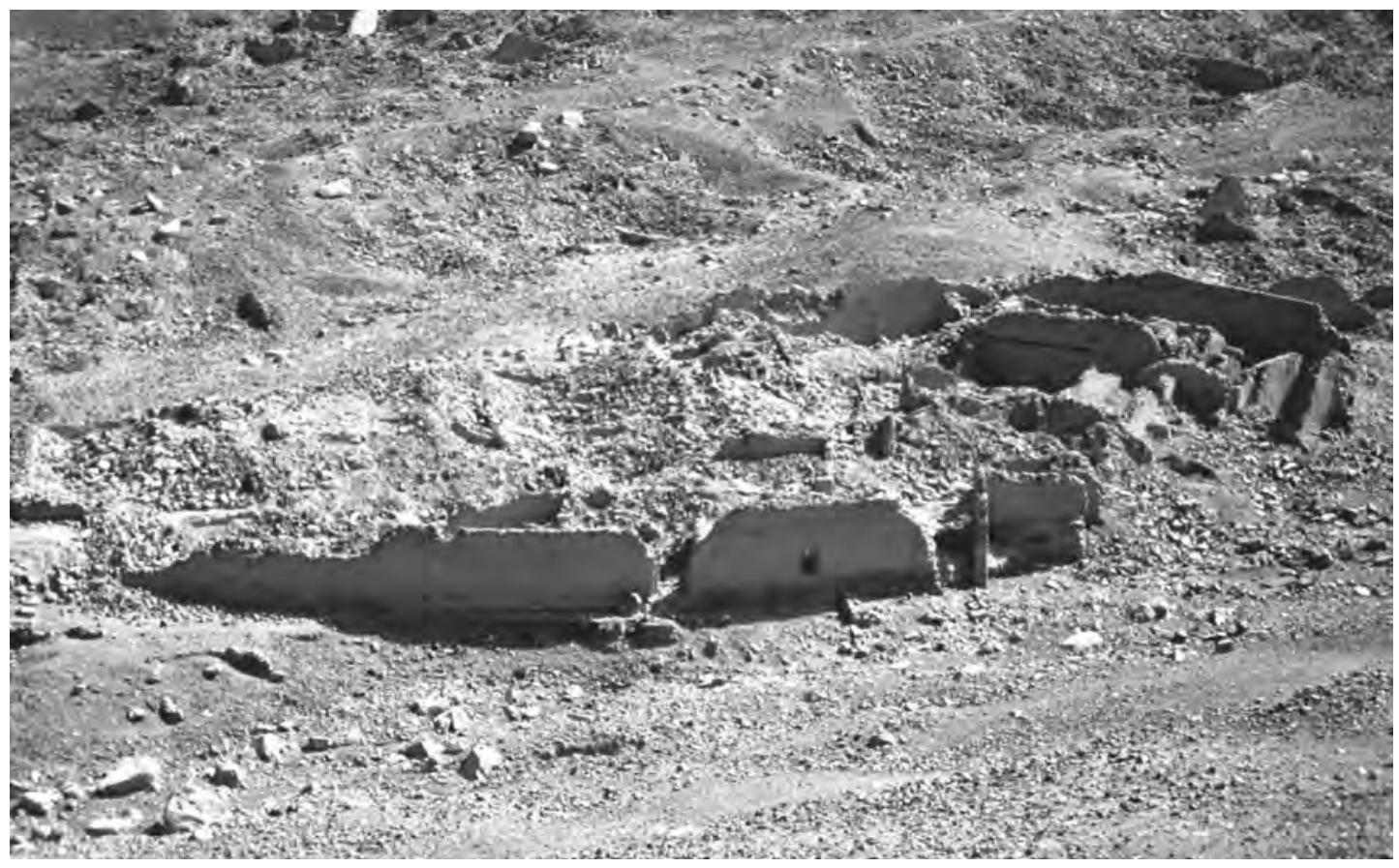

Figura 6. Vista del edificio principal ("Palacio") de La Vuelta.

\section{La Vuelta}

Este sitio se encuentra ubicado a unos 2.5 kilómetros del actual núcleo urbano de Calango ${ }^{3}$ ya unos $410 \mathrm{msnm}$. Se ubica en una quebrada seca muy larga que ha sufrido numerosas cargas aluviónicas, las mismas que han impactado en la arquitectura y han desfigurado su plano arquitectónico, socavando incluso las principales estructuras arquitectónicas.

Demás esta decir que, como le ocurre a la mayoría de los asentamientos prehispánicos abandonados a su suerte, éste ha sido presa de la destrucción de huaqueros y, en este caso concreto por la ocupación temporal de pastores de cabras. Aun así, en la actualidad La Vuelta, se caracteriza por presentar sectores bien definidos y el área de estructuras según Williams y Merino ocuparía de 30 a 35 hectáreas.
Además de los edificios principales, se dispusieron grandes espacios abiertos o plazas trapezoidales, sobre todo en la parte del acceso desde el valle. Williams y Merino reportan hasta 3 de ellas (una con las siguientes dimensiones: $40 \times 70 \mathrm{~m}$ ). Obviamente, había congregación y concentración de grandes grupos de personas. Asimismo, se reportan pequeñas plataformas relacionadas a dichas plazas.

Williams y Merino dividieron el núcleo urbano del asentamiento (de unos $450 \mathrm{~m}$ x $100 \mathrm{~m}$ de ancho) en "7 barrios"y "dos edificios principales". Para una detallada descripción de estos se puede recurrir a su texto, aunque la descripción que hacen de estos "barrios" es bastante sintética por la destrucción que sufrieron dichas estructuras. Asimismo, el aparente condicionamiento del terreno por la estrechez de la quebrada y los posi-

\footnotetext{
${ }^{3}$ Calango, parece haber sido un sitio importante durante la ocupación Inca y quizá antes. De hecho, allí se encuentra localizado el petroglifo más importante del valle (Núñez Jiménez 1986). Sobre las estructuras prehispánicas se ha construido el actual pueblo que ha completado la destrucción parcial del sitio que parece haberse iniciado con las descargas aluviónicas que ha sufrido esta área. Aún así, es común que cada vez que se abre la tierra se hallen restos arqueológicos, sobre todo de época Inca.
} 
bles eventos de huayco que ha soportado, han condicionado una descripción precisa y jerarquizada. Solo se puede decir aquí, que estos "barrios" se componen de estructuras o recintos rectangulares aglutinados con muros hechos con piedra canteada y revestidas de barro, algunas de ellas incluyendo cámaras funerarias colectivas. Una cosa interesante es que Williams y Merino en su "Barrio VII" reportan "tímpanos" en un edificio, lo que supondría la existencia de edificaciones con techos "a dos aguas", un elemento Inca traído de la sierra. En ese mismo edificio Williams y Merino reportan una hornacina con doble lateral escalonado. Cuandoacudimos al asentamiento muchos de éstos y otros elementos habían desaparecido.

Nosotros nos concentraremos en la arquitectura de los edificios principales o arquitectura monumental, que es la que mejor se ha conservado, y que sería infraestructura destinada a funciones político-administrativas o de residencia del grupo dirigente encargado de las instalaciones. Otros edificios cercanos a los principales tendrían otras funciones que por ahora desconocemos. Otras instalaciones estarían relacionadas con actividades económicas como: terrazas agrícolas, corrales y depósitos.

Dentro del sector monumental sobresale un edificio de buena conservación (conocido por los pobladores actuales como el "Palacio") (figura 6) que es el único actualmente en esta parte del valle que mantiene la principal característica de la arquitectura imperial Inca, nos referimos al vano de acceso de forma trapezoidal con doble jamba (figura 7).

La construcción del edificio fue realizada con distintos materiales. La mayor parte de los muros se levantaron con piedras trabajadas unidas con barro, en otros se añadieron adobes hechos en molde de gran tamaño, una técnica exclusiva de la época Inca, en edificios importantes de la zona.

Al frente de este "Palacio", existe otro edificio importante en el que, además de los adobes utilizados para su construcción, existen muros dobles con cámaras funerarias, galerías funerarias techadas con madera y con piedra. Un elemento interesante en la técnica constructiva es la utilización de piedras que sobresalen de los muros y que servirían para el apoyo de maderas para el sos-

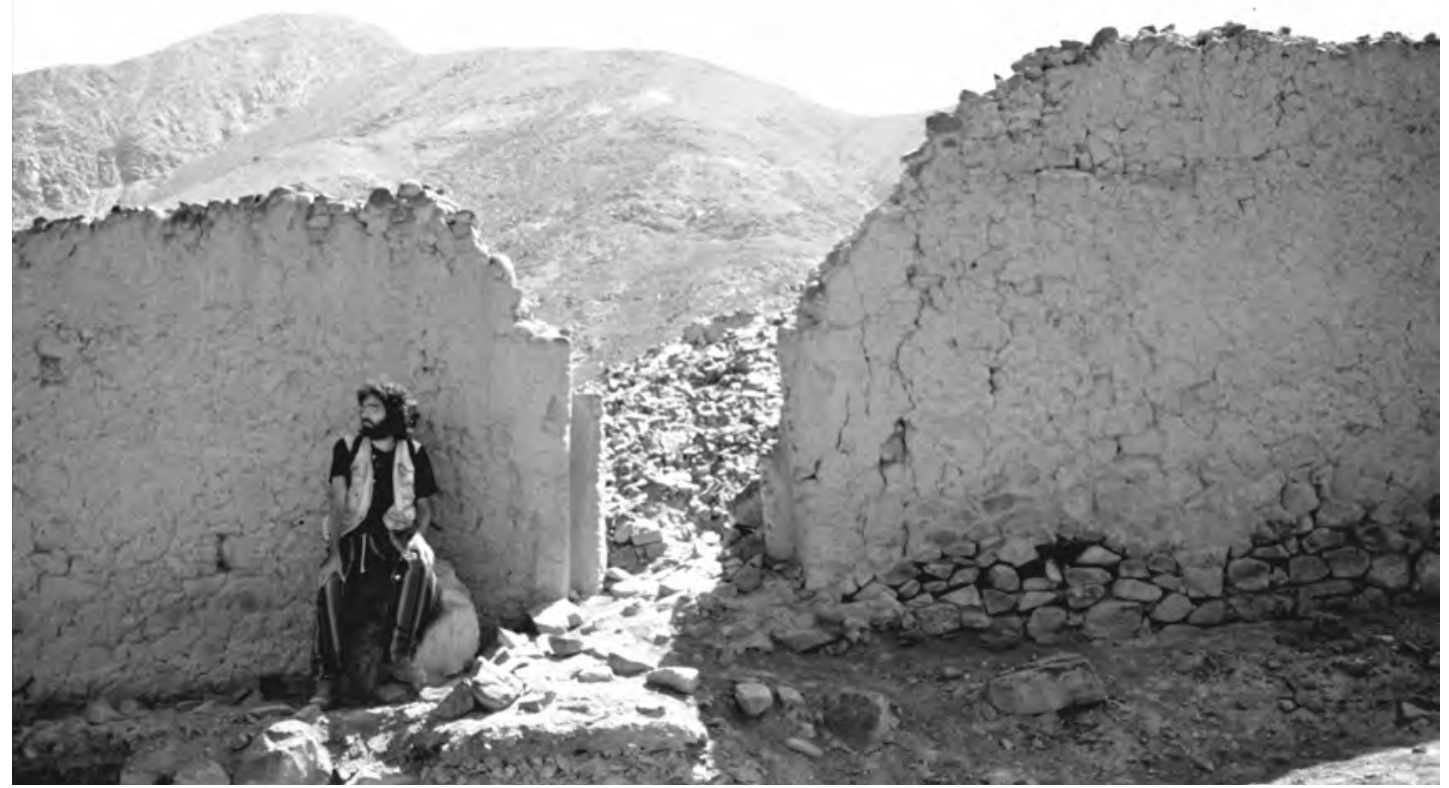

Figura 7. Acceso al edificio principal (figura 6) de La Vuelta. Aunque muy destruido se puede notar las características de la arquitectura inca. 


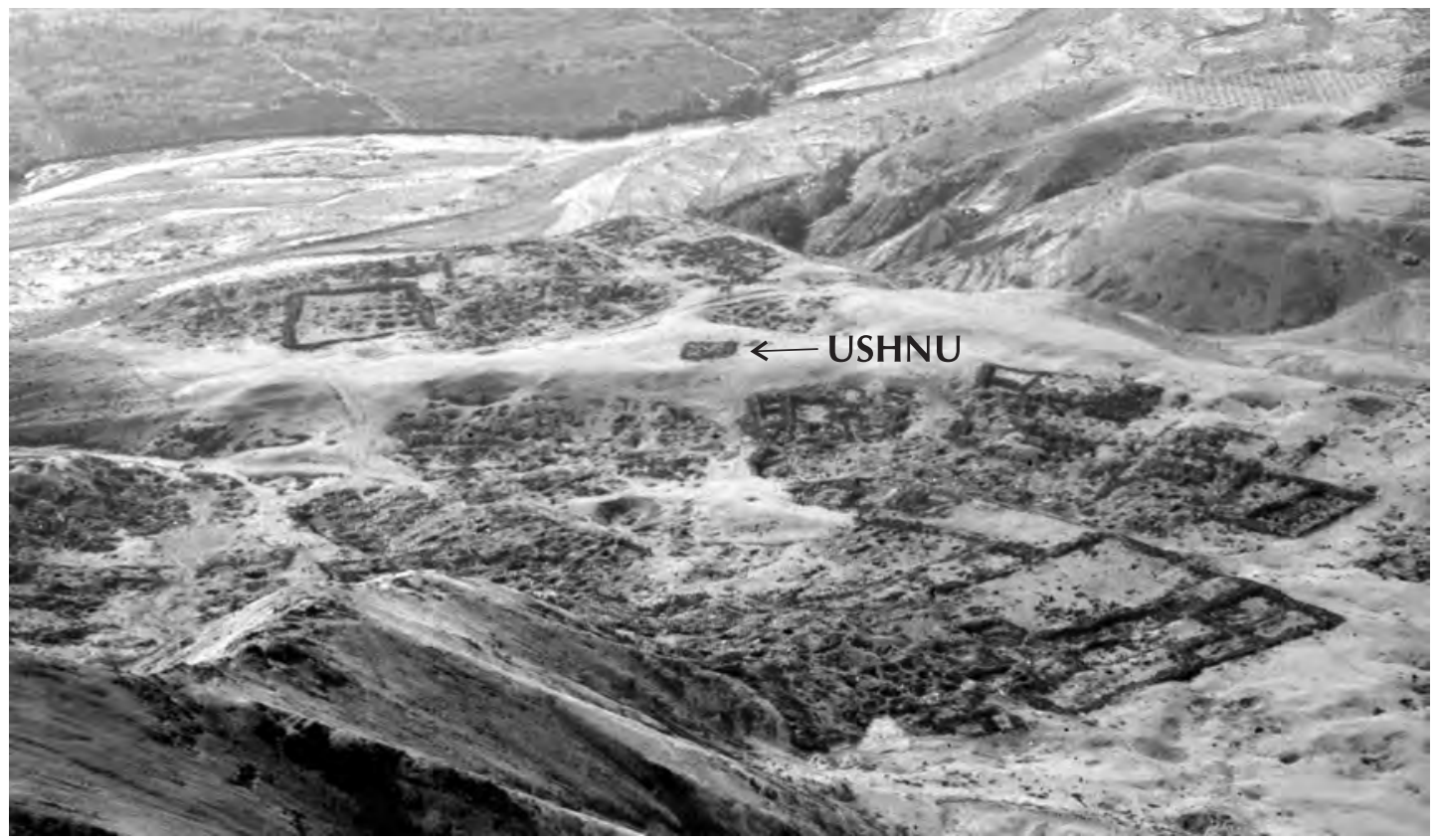

Figura 8. Vista general de Piedra Angosta. Se pueden apreciar sus principales sectores. Nótese como el posible Ushnu, ubicado en el centro del sitio, es el eje del asentamiento.

tenimiento de un segundo piso. Se ha observado que tanto en éste como en el anterior edificio antes descrito, la existencia de un elemento extraño para la arquitectura Inka (aunque no para el valle pues también se registra en un edificio Inca en Piedra Angosta) y que es la inclusión de huesos largos de humanos y camélidos en los paramentos murarios.

Otra cosa significativa es que, como en muchos sitios del mismo valle, la cerámica típicamente Inca es escasa y más bien la Puerto Viejo se hace más recurrente.

\section{Piedra Angosta}

Al parecer este asentamiento fue construido en un área libre de ocupación previa. La mayor parte del asentamiento (entre 8 y 10 ha.), sobre todo lo que al parecer son las áreas públicas y edificios de administración y religión, se localizó sobre una extensa área bastante plana y regular que se eleva del fondo del valle unos 40 metros y localizada a unos $230 \mathrm{msnm}$. (figura 8). La vista que se domina desde el borde de esta explanada permite controlar un gran sector del valle. Esta explanada se encuentra limitada por dos quebradas que restringen el área de construcción del asentamiento, siendo la quebrada que se encuentra al nor-este la entrada natural al mismo. Sin embargo, parece que el acceso más difícil ubicado al sur-oeste del sitio, y que le da el nombre al lugar, es el que se utilizó preferentemente debido a su mejor control desde dentro del asentamiento.

Existen varios sectores, pero nosotros diferenciaremos sólo tres: área de depósitos y cementerio, área de edificios administrativos y religiosos y área de residencia del grupo dirigente del asentamiento. Existen otros sectores que, al parecer, correspondían a espacios domésticos pero son conjuntos pequeños y dado el gran saqueo de las tumbas incluidas dentro de las viviendas (o posterior a su utilización como tales) se encuentran bastante desfigurados.

Estos, además, se hallan en la parte baja del cerro vecino que cierra la explanada del asentamiento, por lo que la pendiente superada median- 
te terrazas condiciona su emplazamiento tornandodifícil sudescripción.

$\mathrm{Al}$ ingresar al asentamiento, se percibe de entrada, que para construir los principales edificios administrativos Inca se eligió la parte más plana. Esta amplitud de espacio les permitió a los constructores, al contrario que en La Vuelta constreñida por los cerros, dejar grandes espacios entre edificios y contar con espacios públicos que sin estar delimitados a modo de plazas parecen haber cumplido esa misma función como veremosacontinuación.

El área de depósitos y cementerio está caracterizado por una gran estructura cuadrangular (33 m por lado), la que esta delimitada y cercada por un muro de piedra y que en el interior comprende una serie de estructuras rectangulares subterráneas $(3 \times 3 \mathrm{~m})$ con los paramentos internos enlucidos con barro fino que sugieren su utilización como depósitos o "colcas" (figura 9). Esta área sería ideal para dicha función, puesto que, como en la mayoría de centros administrativos Inca las colcas se hallaban en las zonas más venti- ladas y con mayor circulación de aire, para la consecuente conservación de los productos allíalmacenados. Asimismo, los productos también serían depositados, por sus transportadores, inmediatamente después de ingresar al asentamiento.

Contigua a esta estructura, no sabemos si contemporánea, se halla una gran área de tumbas. Los fardos funerarios presentan textiles típicos inca y la cerámica Puerto Viejo está presente.

Dejando atrás el área anterior se observa el área de edificios administrativos y religiosos. Pero entre esta área y la anterior existe un gran espacio abierto, que a simple vista no parece cumplir función alguna. Sin embargo, un análisis del asentamiento desde una altura adecuada y la misma fotografía aérea del asentamiento revela la existencia de una plaza. Un elemento definitivo para la comprobación de esta conjetura, y además señalarla como la plaza principal del sitio, es que casi en el centro de este espacio abierto se levanta una pequeña estructura rectangular con un pozo circular contiguo. La pequeña plataforma rectangular esta hecha de piedra y no tiene mucha alzada

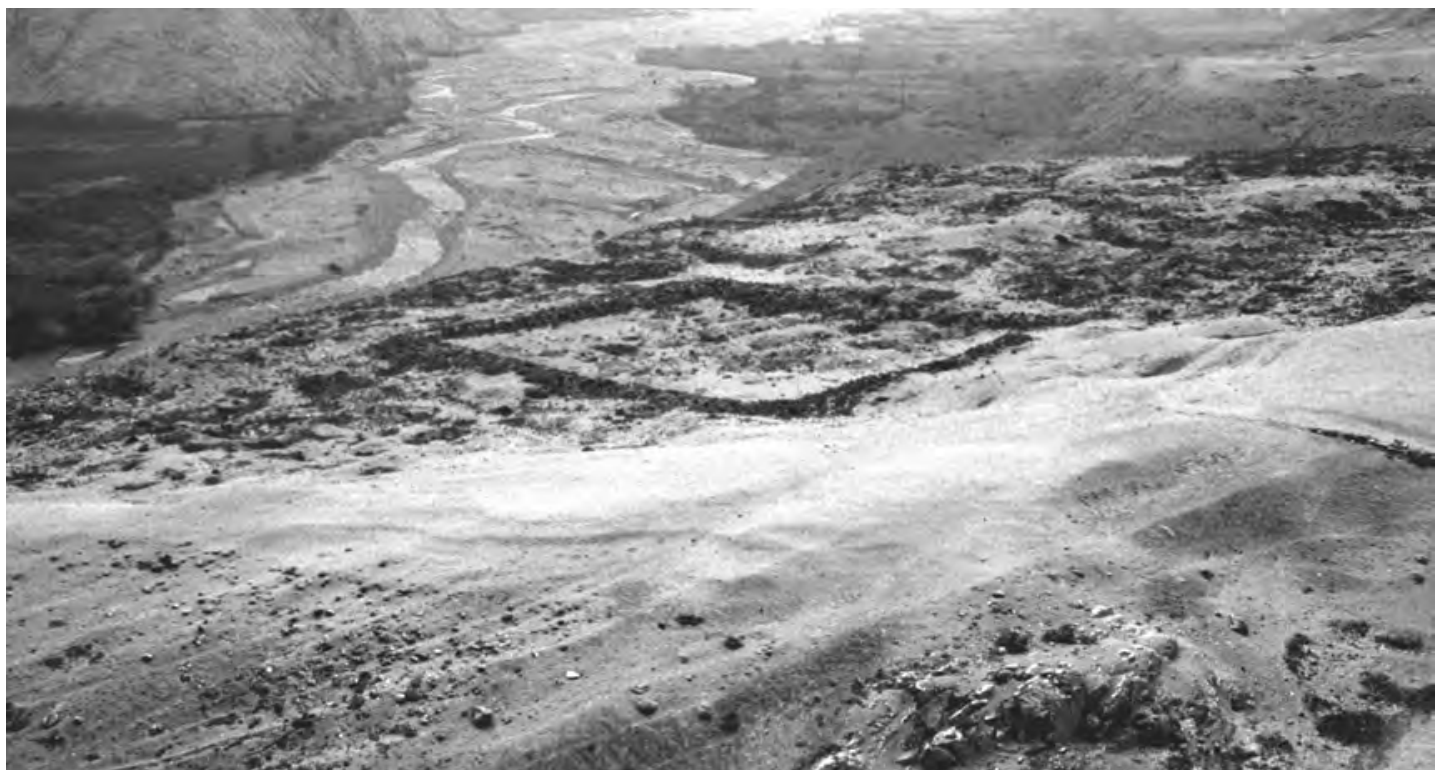

Figura 9. Vista del sector de depósitos y cementerio. En primer plano, la gran estructura cuadrangular que guarda en su seno los depósitos o "colcas". A la derecha se extiende un gran cementerio. 


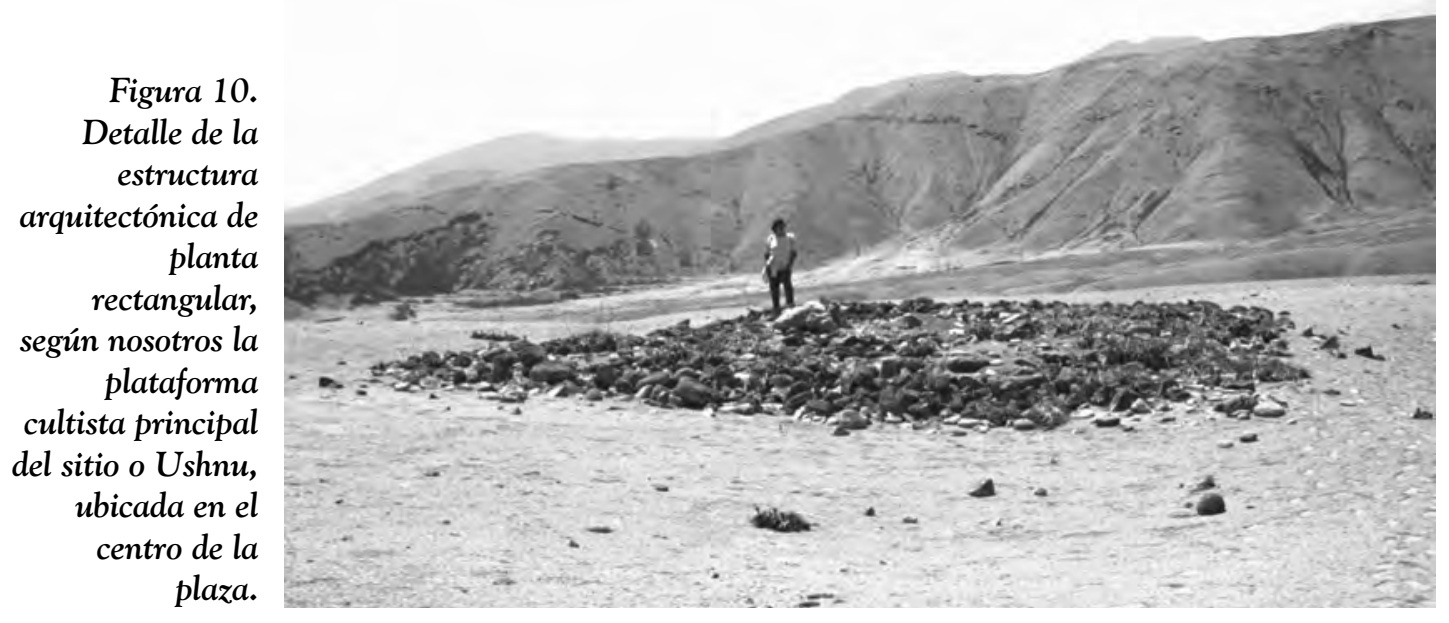

\section{Figura 11. Vista parcial del sector de edificios administrativos $y$ religiosos, tomada desde el sector residencial del grupo dirigente.}

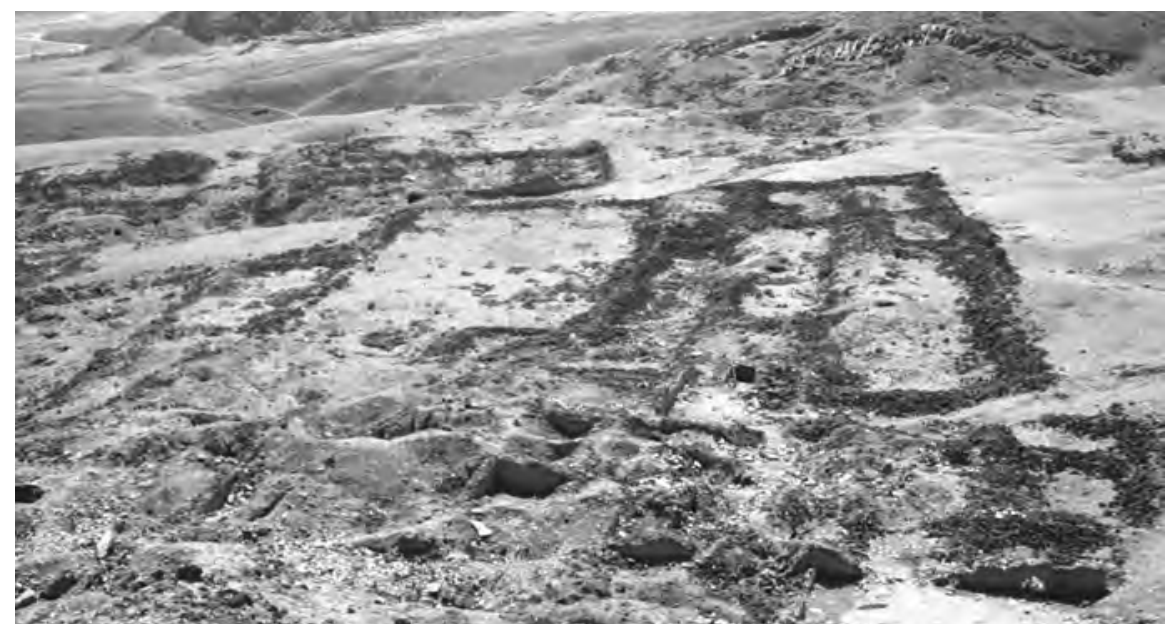

(figura 10). Sin embargo, su morfología, su localización y el elemento accesorio: el pozo (para verter las sustancias que se ofrecían a la tierra o "pachamama" en los rituales), nos plantea que su función haya sido la de un Ushnu, es decir la plataforma desde la que se dirigían y realizaban los principales actos públicos, políticos y religiosos en cada centro administrativo. ${ }^{4}$ Por el momento, este sería el único Ushnu que se ha reportado en el valle de Mala.

Atravesando esta plaza nos hallamos en el área con grandes edificios de plantas rectangulares y que hemos denominado área de edificios administrativos y religiosos (figura 11). Aquítambién Williams y Merino (1976) dicen haber observado algunos edificios con "tímpanos" sugiriendo nuevamente la existencia de techos a dos aguas. En este sector estarían los edificios más importantes del sitio, básicamente los que tienen que ver con las instituciones principales del Estado Inca: los administrativos (políticos) y ligados a ellos los religiosos. En este sector, llama la atención a primera vista, que muchas de las estructuras arquitectónicas principales han sido intruidas por entierros de época Inca. Por ello, es de suponer que existía un templo importante aquí, puesto

\footnotetext{
${ }^{4}$ Para una discusión acerca de las morfologías y funciones del Ushnu ver Hyslop 1990: 69.
} 


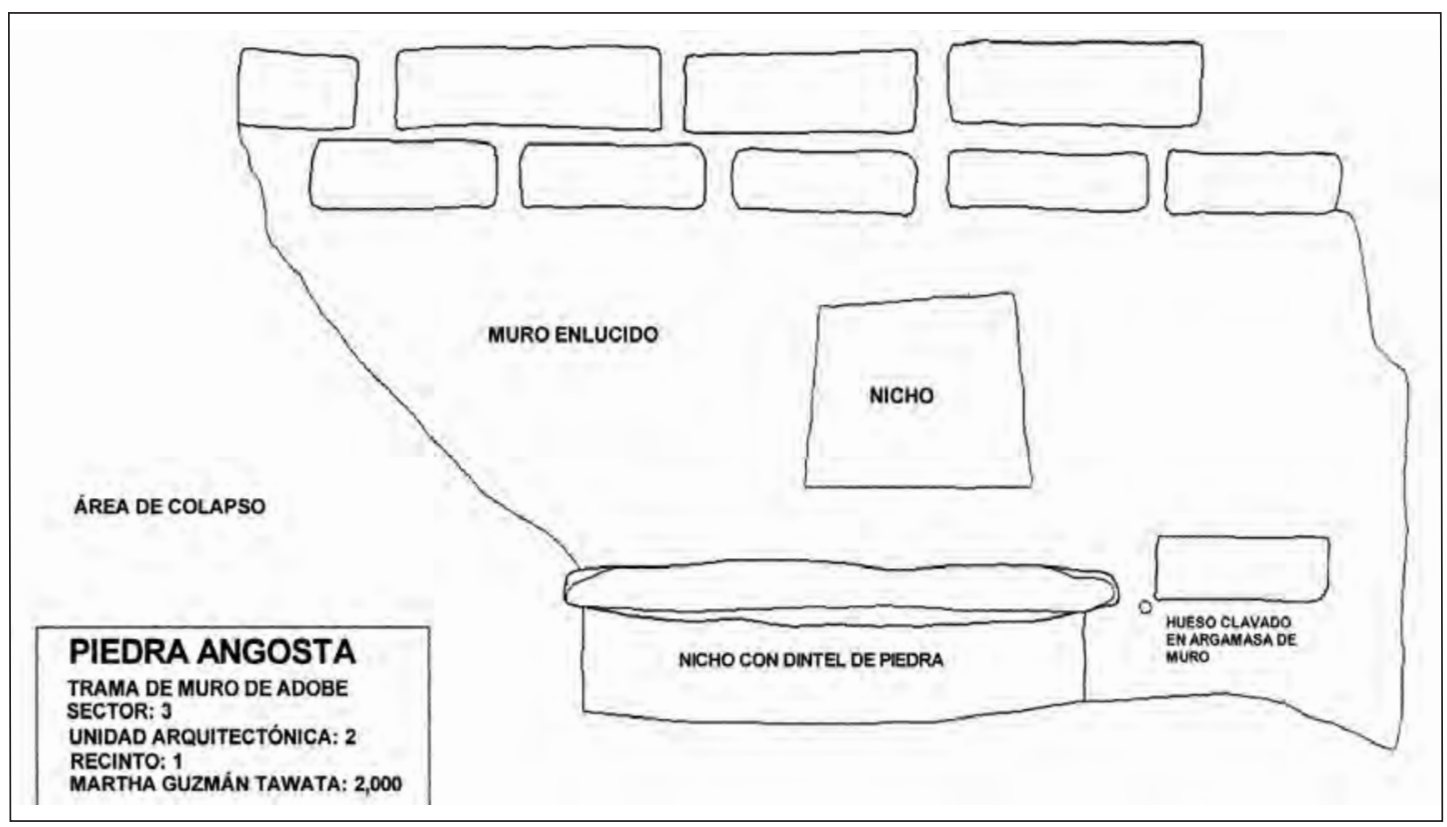

Figura 12. Detalle de Área residencial P[1]. Angosta.

que el entierro en sectores públicos solo se realizaba en edificios de carácter religioso como en los de Pachacamac (Lurin), La Cumbe (Chincha) y para el valle de Mala solo en un sitio más, que luego abordaremos: ElSalitre. Asimismo, la mayoría de los entierros humanos se realizaron cuando la mayoría de las estructuras arquitectónicas ya no estaban en funcionamiento, es decir que el Estado Inca quizá ya había colapsado, probablemente, como consecuencia de la llegada de los invasores castellanos. Williams y Merino nos aportan también un dato interesante y es que ellos observan que algunos cráneos de los cadáveres presentan deformación tabular erecta, una deformación típicamente Inca.

El último sector, el de residencia del grupo dirigente, incluye la parte baja del cerro contiguo a los principales edificios administrativos y que es la parte más resguardada y desde donde se controla todo el asentamiento. Este sector esta construido gracias al aterrazamiento de la pendiente del cerro. Asípues, los edificios se hallan escalonados =y a distinto nivel pero están comunicados entre ellos. Aquí resalta la utilización de adobes Inca, nichos trapezoidales (figura 12) y el enlucido de barro y pintura amarillo ocre (y roja según Williams y Merino) sobre el mismo. Emplazamiento, volumen y color en este tipo de edificios Inca son normas en la arquitectura Incay que tenía como objetivo ejercer un impacto visual en el visitante al asentamiento.

\section{Pachacamacy su influencia en el valle de Mala}

Es importante señalar la relación de las sociedades de esta área con el principal centro de poder político-ideológico de la costa central: Pachacamac, ubicado en la margen norte de la desembocadura del río Lurín, Lima. Este centro de culto (reconocido por los pobladores andinos como un "oráculo") es relevante aquí porque ejerció un gran poder ideológico sobre los valles costeros ${ }^{5}$ y también en áreas serranas antes y durante

\footnotetext{
${ }^{5}$ En Pachacamac se han hallado numerosos contextos funerarios que incluyen textiles y cerámica de valles tan
} 
la época Inca. ${ }^{6}$ Consecuentemente, habría mantenido alguna relación con la sociedad local del valle de Mala. Dicha relación religiosa no tiene que ser confundida con un control político exclusivo de la elite dominante sobre el valle de Mala, como se ha venido planteando desde la interpretación de la etnohistoria, territorialidad actualista y contextos cerámicos en un sitio como Pachacamac que además articulaba a toda una serie de localidades ubicadas en el seno de sociedades autónomas.

Llagábamos al supuesto de ese tipo de relación de Mala con Pachacamac de dos formas: una directa y otra indirecta. La primera, ya la habíamos esbozado al iniciar nuestro trabajo al recopilar la información necesaria para apoyar nuestras hipótesis de trabajo para el valle de Mala. Resulta que habíamos reconocido dentro de los contextos excavados por el investigador alemán Max Uhle en Pachacamac, un conjunto cerámico singular con características del estilo Puerto Viejo (Uhle 1991[1903]: fig. 82-83 y lám. 13: fig. 6. También ver Bueno 1982: 26 fig. a) y que suponemos que procede del área de Mala donde se estaba produciendo en esos momentos. ${ }^{7}$ Estos conjuntos cerámicos provenían específicamente del sector denominado por Uhle como "Outer City" ("Ciudad exterior") (Uhle 1991[1903]: 62-66) y "Suburbio" o "Barrio" por Shimada (1991: XX, LV y ver Lámina 2) y que sería uno de los lugares en la periferia de Pachacamac escogido por el grupo social del valle bajo-litoral de Mala del Intermedio Tardío y/o Inca para establecer un asentamientoenclave en el centro religioso. Es conocida por diversas referencias etnohistóricas (Rostworowski 1992: 92) la peregrinación periódica que se realizaba a este centro de culto. Por consecuencia, los diferentes grupos sociales deberían utilizar un espacio concreto donde permanecer durante los actos religiosos, sobre todo cuando Pachacamac tenía una relación ideológica con Mala comoveremos más adelante. En el futuro, excavar este u otros sectores de Pachacamac seguramente supondrá el reconocimiento de concentraciones de conjuntos arquitectónicos y cerámicos particulares que definirían ocupaciones humanas procedentes de un área geográfica concreta, como la de Mala.

Por otro lado, la evidencia indirecta de esta relación proviene de la etnohistoria (Santillán 1927[1563]: 30). Según ésta, durante la expansión del Imperio incaico, el gobernante Tupac Inca Yupanquillega a Pachacamac, oráculoal que supuestamente respetay que quiere asimilar dentro de la religión oficial solar. En dicha visita el dios Pachacamac, mediante sus sacerdotes, pide al Inca que construya "casas para sus hijos" en los valles costeros de Mala y Chincha y en Andahuaylas (Patterson 1991: 89). Para nosotros, mediante la metáfora de los hijos, se estarían señalando lugares importantes, económicamente hablando, para los dirigentes de Pachacamac. En estos lugares se explotarían ciertos recursos económicos (principalmente, tierras para producción agrícola según Rostworowski 1992: 51) en el nombre de Pachacamac dentro de una estrategia de coerción ideológica. De hecho, Pachacamac era una deidad a la cual se temía por su relación con los movimientos sísmicos tan comunes y destructivos en la zona andina, sobre todo en la costa (Patterson 1991: 9). Planteamos que durante la época Inca la materialización de estos hijos se produjo mediante la construcción de edificios singulares (lugares de culto o "huacas") que reproducirían el culto de Pachacamac pero al cual inteligentemente solaparon el de su

alejados del Lurín como del área Chimú o Chincha (Uhle 1991 [1903]). Adicionalmente, la etnohistoria recoge varios relatos donde se expresa la peregrinación periódica de poblaciones a dicho centro de culto (v.gr. Rostworowski 1992).

${ }^{6}$ Para mayores referencias arqueológicas y etnohistóricas acerca de Pachacamac se puede recurrir a la recopilación bibliográfica de Ravines (1996).

${ }^{7}$ Como ya vimos, la asociación entre asentamientos domésticos en Mala y producción cerámica Puerto Viejo, es bastante clara según nuestro reconocimiento y las investigaciones de Engel en los años ' 70, inéditas y depositadas en el CIZA. 
propio dios: el Sol o Inti. Dichos "edificios satélites" seguían el patrón arquitectónico del Templo del Sol construido por los Inca en Pachacamac: edificios con elementos arquitectónicos Inca (como los vanos trapezoidales) instalados en las cumbres de cerros que dominan la desembocadura de un río y el litoral circundante que incluye islas. De esta manera, para el valle de Mala el sitio construido durante la época Inca bajo el título de "hijo de Pachacamac" seríaEl Salitre (Figura 13y 14) y que también siguiendo a Albornoz (1967 citado en Rostworowski 1992: 55) podría ser esa "huacaprincipaldel valle ubicada en un cerro a orillas del mar" conocida como "Sulcavilca" (aunque este autor se refiere a éste como un "hermano de Pachacamac"). Como mencionamos arriba en este sitio existe una gran área de enterramientos que ocupa casi toda la ladera de un cerro, práctica que se realizaba en sitios considerados sagrados.
Todo lo anterior apoyaría nuestra evidencia directa de la existencia de grupos de pobladores del valle de Mala en Pachacamac, que transportaban con ellos entre otros productos la cerámica Puerto Viejo, en clara respuesta a esa relación directa con el oráculo. Por lo mismo, el sitio de Pachacamac también debe ser reconocido, además de lugar de apropiación de productos por la clase dirigente, como un espacio para la distribución y consumo de bienes entre diferentes grupos sociales controlado primero por los dirigentes de Pachacamac yluego por los Inca.

\section{Comentarios finales}

Por el momento y a la espera de mayores investigaciones en elárea, deberemos conformarnos con plantear la presencia de dos grupos sociales que co-existieron en el valle de Mala antes de la llegada de los Inca. Estos, cayendo en el riesgo

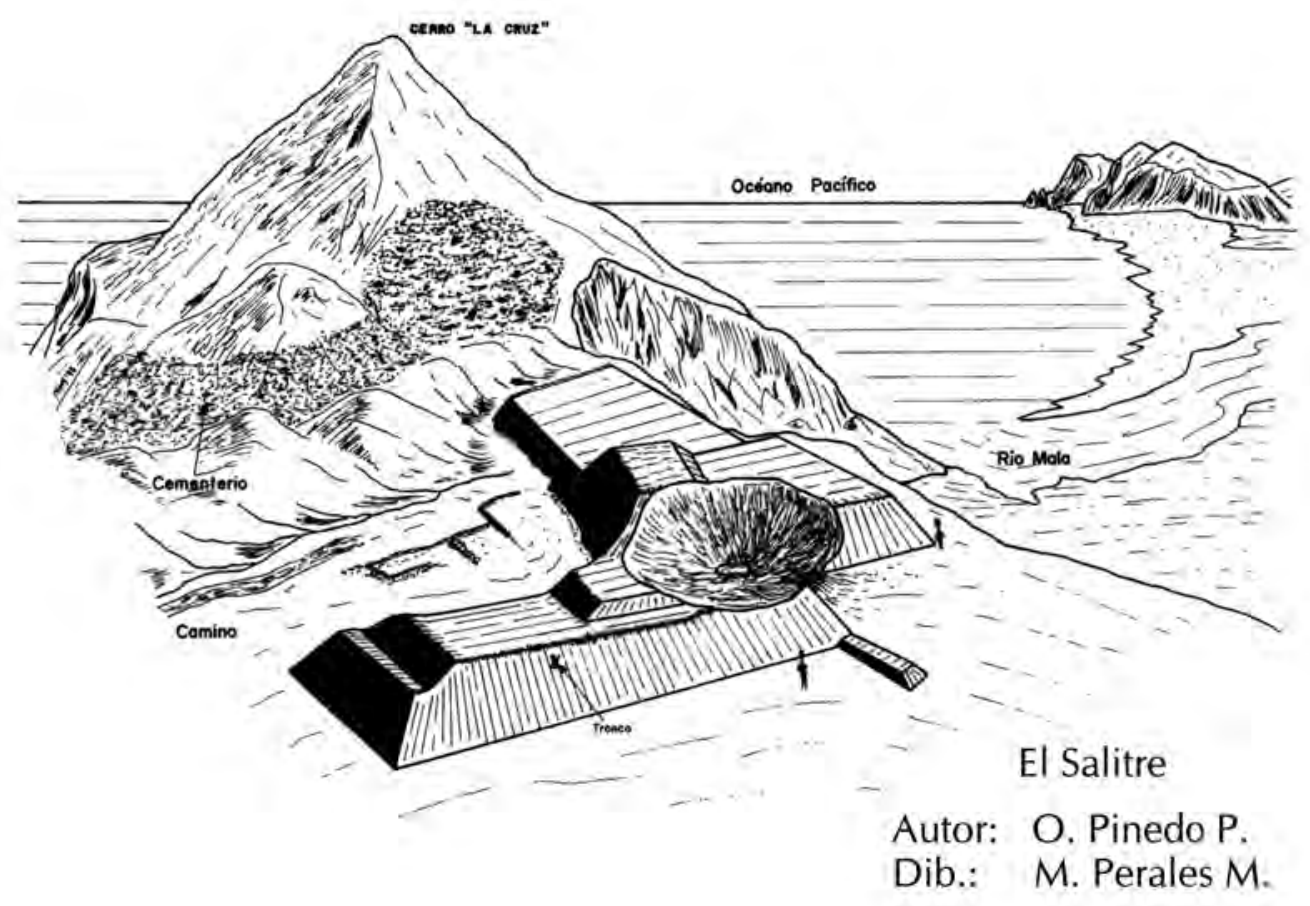

Figura 13. Reconstrucción de la plataforma principal de El Salitre. 


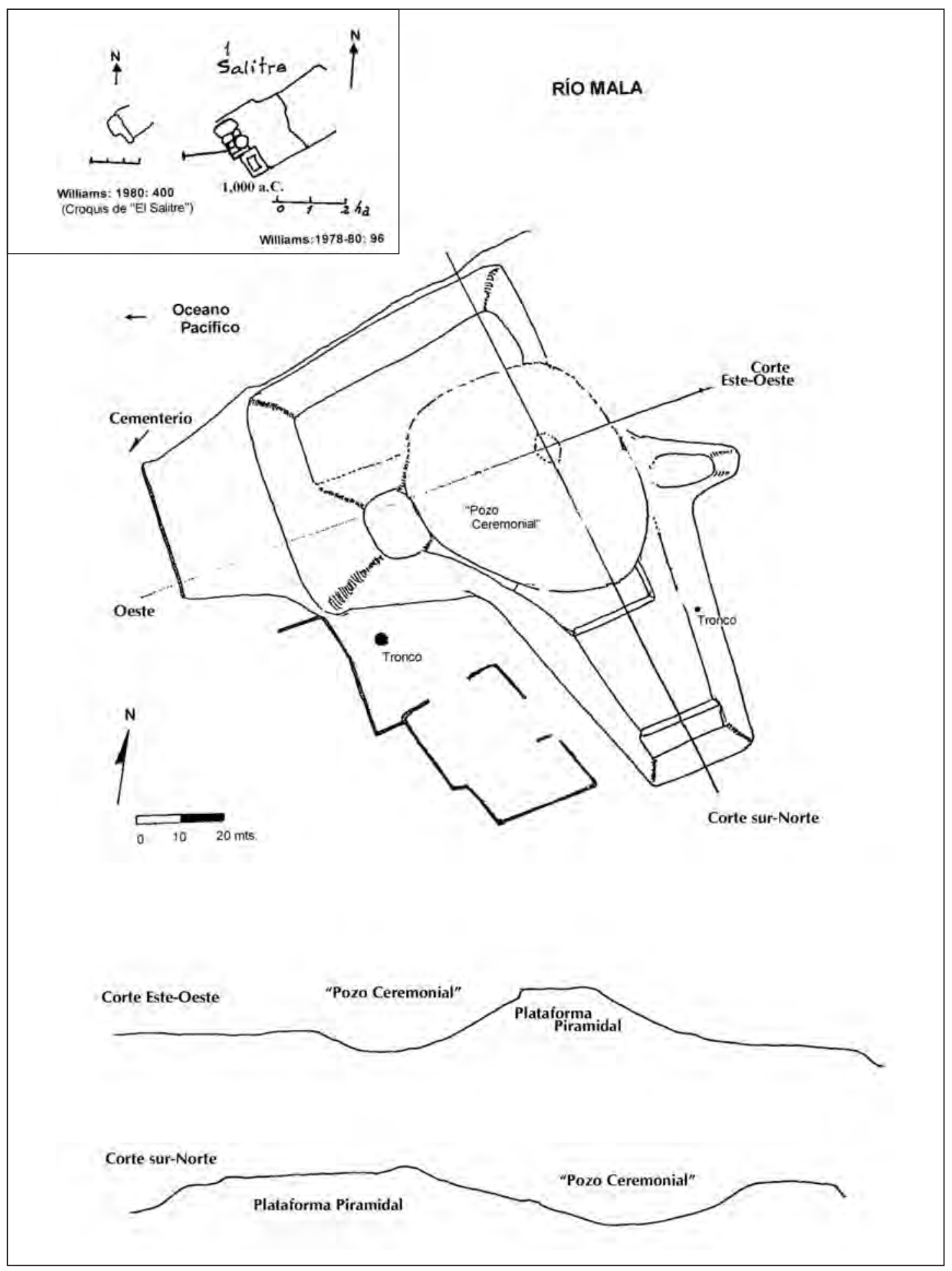

Figura 14. Plano y cortes de la plataforma principal de El Salitre. 
de la simplificación, se podrían dividir en grupos de valle medio y los del valle bajo-litoral. Los primeros con una arquitectura semejante a la serrana, cerámica simple y doméstica, entierros en mausoleos dentro de las casas, asentamientos relacionados a tierras agrícolas y acceso a las aguas del río Mala.

El segundo, supondría una sociedad de una economía mixta de explotación de recursos marinos (en el litoral) y de agricultura en las zonas de la desembocadura del río. Aquí, como en el caso del grupo social anterior la topografía podría estar condicionando estas formas diferentes de asentamiento, aunque la arquitectura y la cerámica tienen cualidades diferentes. En el grupo del valle bajo-litoral la cerámica policroma (Puerto Viejo) de fino acabado con formas mayoritariamente no-domésticas respondería a una producción de escala supra-doméstica. De hecho, podríamos estar ante un grupo social especializado en producción cerámica y orientado hacia la explotación de recursos marinos y a su procesamiento en terrazas de secado.

Sin embargo, ambos grupos sociales descritos arriba tendrían una forma de vida colectiva con poca asimetría social entre ellos, pues no hemos apreciado la materialización de un control exclusivo de recursos naturales o concentración y/o explotación de mano de obra materializada en grandes estructuras arquitectónicas.

Sobre esta forma de vida colectiva, la invasión Inca del valle de Mala supondrá una reorientación de las actividades económicas de explotación de los recursos naturales de manera autosuficiente para la misma población hacia una explotación del trabajo de la sociedad local en beneficio de los Inca. Por eso, cobra sentido, que en este valle los asentamientos humanos autóctonos sigan funcionando y produciendo, por ejemplo, la cerámica Puerto Viejo. ${ }^{8}$ Por eso tiene senti- do que los Incas no movilicen poblaciones ni se creen nuevos asentamientos domésticos en esta época. La mayoría de los asentamientos autóctonos del valle se localizaban en zonas no defendibles, puesto que como decíamos arriba no existiría concentración económica ni poder político que la defendiese y, consecuentemente no revestían una amenaza como organización sociopolíticaal poder cuzqueño.

La construcción de los asentamientos Inca cobra sentido desde la óptica de un Imperio: la explotación de recursos económicos con y mediante la mano de obra autóctona. Asimismo, los centros administrativos Inca no estaban emplazados en zonas inaccesibles por barreras naturales o artificiales (murallas). Por eso creemos, que los Incas controlaron el valle de una manera rápida y efectiva, situación que por ejemplo no se dio en el vecino valle de Cañete, donde se levantaron infraestructuras militares, como el sitio de Inkawasi (Hyslop 1985). Solo en el caso de Piedra Angosta se empleó un lugar que controlaba el espacio circundante y, aparentemente, sin el control directo de algún recurso natural. La respuesta del porqué de la elección de este emplazamientoy, más importante qué se controlaba o protegía, se deberá dilucidar mediante la investigación arqueológica.

Finalmente, hemos reconocido que Pachacamac, más allá del relato etnohistórico, (sos) tuvo una gran influencia en el valle de Mala antes y durante la ocupación Inca. Comprobar el grado y tiempo de explotación real del centro de Pachacamac con relación a sus vecinos es una cuestión que se deberá investigar también desde la arqueología localizando esos puntos espaciales a los que se hacen referencia como "hijos", "hermanos" o "esposas" de Pachacamac y ver en que medida esas relaciones (de dependencia) generaban o no, una explotación económica enmascaradayjustificada mediante una ideología religiosa.

\footnotetext{
${ }^{8}$ De hecho, la producción cerámica y otras podrían haberse controlado y aumentado durante esta ocupación. Por ejemplo, la cerámica Puerto Viejo ha sido hallada en lugares tan alejados de su centro de producción como en Armatambo, Lima (Hyslop y Mujica 1992) o en la Isla San Lorenzo (Isla 1995: fig. 3a y 6d), lo que supone que había una mayor distribución y consumo de la misma en época Inca.
} 
Acerca de la ocupación Inca del valle bajo del Mala

\section{Agradecimientos}

Deseamos agradecer a Bernardino Ojeda, quien nos enseñó desinteresadamente la arqueología del valle de Mala en ese viejo edificio del CIZA que se resistía a ser abandonado. Agradecemos también a las innumerables personas que durante todos estos años nos apoyaron física, intelectual y emotivamente. En especial, a Carmen Pérez Maestro quien nos acompañó en nuestras primeras prospecciones y a Marillyn Holmes que estuvo siempre a nuestro lado. A amigas como Evelyn Guevara, Martha Guzmán, Diana León y Julissa Ugarte quienes se involucraron de diversas formas con nuestro trabajo. Asimismo, a los maleños y maleñas que en su momento nos apoyaron sin pedir nada a cambio.

\section{Bibliografía}

Bonavía, Duccio

1959 Cerámica de Puerto Viejo (Chilca). Separata de Actas del II Congreso Nacional de Historia del Perú: 137-168. Museo de Arqueología. UNMSM.Lima.

1991 Perú. Hombre e Historia. De los Orígenes al SigloXV.Edubanco. Lima

Bueno, Alberto

1982 El Antiguo Valle de Pachacamac. Espacio, Tiempo y Cultura. Boletín de Lima, 25. Lima.

Chávez, Julio

2002 Institucionalidad del Riego en el Valle de Mala: Las Reglas de Operación de los Usuarios Regantes de Calango. Perú: El Problema Agrario. Sepia IX. Lima.

Coello, Antonio

1993 Los Coayllo: Una Ocupación durante el Intermedio Tardío. Una Visión Etnohistórica. Sequilao, Año II NŸ2. Lima.

Eechkout, Peter

1999 Pachacamac durant 1'Intermédiaire Récent. Étude d'un Site Monumental Préhispanique de la Côte Centrales du Pérou. BARInternationalSeries 747.
Engel, Fréderick

1982 Man, Settlement and Environment in the Andes. Chilca. Centro de Investigación de Zonas Áridas. Universidad Nacional Agraria. Lima.

Gabe, Carmen

2000 Investigaciones Arqueológicas en el Cerro Salazar-Mala. Centro de Estudios Arqueológicos y Medio Ambiente. Serie Investigaciones Arqueológicas, 1. Lima.

Goldfried, Howard

1969 El Salitre: Un Centro Religioso en el Valle de Mala. Mesa Redonda de Ciencias Prehistóricas y Arqueológicas. TomoII: 167-174.PUCP.Lima.

Guzmán Tawata, Martha

2000 Piedra Angosta: Ocupación Tardía en el valle de Mala y las Manifestaciones de un Imperio. Informe Inédito de Practicas Pre-Profesionales. U.San Marcos. Lima

Hyslop, John

1985 Inkawasi, the New Cuzco. B.A.R. International Series No. 234. Oxford.

1990 Inka Settlement Planning. University of Texas Press. Austin.

Hyslop, John y Elías Mújica

1992 Investigaciones de A. Bandalier en Armatambo (Surco) en 1892. Gaceta Arqueológica Andina, 22: 63-86. INDEA. Lima.

Isla, Johnny

1995 Materiales recuperados por Max Uhle (1906-1907) en la Isla de San Lorenzo, Costa Central del Perú. Gaceta Arqueológica Andina, 24: 73-91. INDEA. Lima.

Morales, Daniel

1993 Compendio Histórico del Perú. Ed. Milla Batres. Lima.

Nuñez Jiménez, Antonio

1986 Petroglifos del Perú. Editorial CientíficoTécnica. LaHabana

Patterson, ThomasC.

1991 The Inca Empire. The Formation and Disintegration of a Pre-Capitalist State. Berg. New York 
Ravines, Rogger

1996 Pachacamac. Santuario Universal. Editorial Los Pinos. Lima

Rostworowskide Diez Canseco, María

1992 Pachacamac y el Señor de los Milagros. Una Trayectoria Milenaria. IEP.Lima

Santillán, Hernandode

1927[1563] Relación del Origen, Descendencia, Política de los Incas. Colección de Libros y documentos referentes a la Historia del Perú. T. IX, 2da. Serie. Lima.

Shimada, Izumi

1991 Pachacamac Archaeology: Retrospect and Prospect. Introduccion a Pachacamac. A Reprint of the 1903 edition by Max Uhle. University of Pennsylvannia. Philadelphia

Strong, William y Gordon Willey

1943 Archaeological Studies in Peru, 19411942. Columbia University Press. New York.

Tantaleán, Henry

1995 El Intermedio Tardío en la Desembocadura del Río Mala. En Echevarria, Gori (ed.): El VI Congreso Nacional de Estudiantes de Arqueologíay la UNMSM: 65-73. Lima.

1996 Patrón de Asentamiento del Intermedio Tardío de la Parte Baja del Valle de Mala. Informe presentado al curso "Taller de Arqueología". E.A. P. de Arqueología.
Facultad de Ciencias Sociales. UNMSM. Lima.

Tantaleán, Henryy Carmen Pérez

1997 Los Incas en el Valle de Mala. Confusión, Año II, NŸl2.Lima.

Tantaleán, Henry y Omar Pinedo

s/f El Salitre: ¿Límite Meridional de los Templos en "U"?. Manuscrito en posesión delos autores.

Tello, JulioC.

1959 Paracas. Primera Parte. Vol. 1. Publicación antropológica del Archivo "JulioC. Tello" delaUNMSM. Lima.

Uhle, Max

1991[1903]Pachacamac. A Reprint of the 1903 edition by Max Uhle. The University Museum of Archaeology and Anthropology. University of Pennsylvannia. Philadelphia.

VillarCórdova, Pedro

1931 Arqueología del Departamento de Lima. Lima.

Williams, Carlos

1980 Complejos de Pirámides con Planta en U. Patrón Arquitectónico de la Costa Central. Revista del Museo Nacional, TomoXLIV:95-110.Lima.

Williams, Carlosy Francisco Merino

1976 Inventario, Catastro y Delimitación del Patrimonio Arqueológico del Valle de Mala. Instituto Nacional de Cultura. Lima. 